\title{
Acute Compartment Syndrome of Hand in a Pediatric Patient: Intravenous Infiltration and Cannula Dressing as Culprit
}

Neeraj Kumar $\odot$ Abhyuday Kumar $\odot$ Amarjeet Kumar $\odot$ Amit Kumar Sinha $\odot$

\author{
Pediyatrik Bir Hastada Elin Akut Kompartman \\ Sendromu: Suçlu Olarak Intravenöz Infiltrasyon \\ ve Kanül Tespiti
}

Sir,

Acute compartment syndrome (ACS) of the upper extremity due to intravenous cannula dressing is a rare but dreaded condition, especially in the pediatric population. Compartment syndrome is a clinical picture associated with increased pressure in myofascial compartments leading to an alteration in tissue perfusion ${ }^{(1)}$.

In this report, we present a 4-month-old infant who presented with acute compartment syndrome of left hand due to intravenous infiltration which was detected in the operating room before induction of anesthesia and scheduled for Hartmann's procedure under general anesthesia. A 24 G IV cannula had been placed in the child's left hand, and left there for about 12 hours with micropore circumferential bandage over the splint. On examination skin over left hand was tense, pale and mottled (Figure 1, Panel A). There was no active motion of the extremity, and the pain was present on passive movement. Capillary refill time was decreased but the radial pulse was palpable. The bandage was taken out immediately and limb was kept at the level of the heart. After about thirty minutes, swelling over affected limb decreased and pallor resolved. Then we applied 4 drops of topical heparin preparation (Phlebotroy QPS, Troikaa Pharmaceutical Ltd.) containing $1000 \mathrm{IU} \mathrm{ml}^{-1}$ on the affected area and within 2 hours after heparin application the pain, pressure, and edema got resolved (Figure 1, Panel B).

This case highlights the importance of swift diagnosis and management to avoid sequelae related to ischemic insult, i.e., muscle necrosis, neurovascular injuries, and permanent functional deficits. The diagnosis of ACS in infants can be more challenging due to different etiologies, the variability of presentation and inability of its expression by infants. ACS is characterized mainly by 6 P's (pain, pallor, paraesthesia, pulselessness, pressure or firm compartments and paralysis), in our case pain, pallor and pressure or firm compartment were present on local examination.
Received: 06 January 2020 Accepted: 14 February 2020 Publication date: 30 April 2020

Abhyuday Kumar Room No. 15, Opd Block, Department of Anaesthesiology, Aiims Patna, Phulwarisharif 801507 Patna - India

drabhyu@gmail.com ORCID: 0000-0002-9247-6713

N. Kumar 0000-0002-9161-7000

A. Kumar 0000-0002-4272-5750 A.K. Sinha 0000-0002-8909-7819 AlIMS Patna, India 


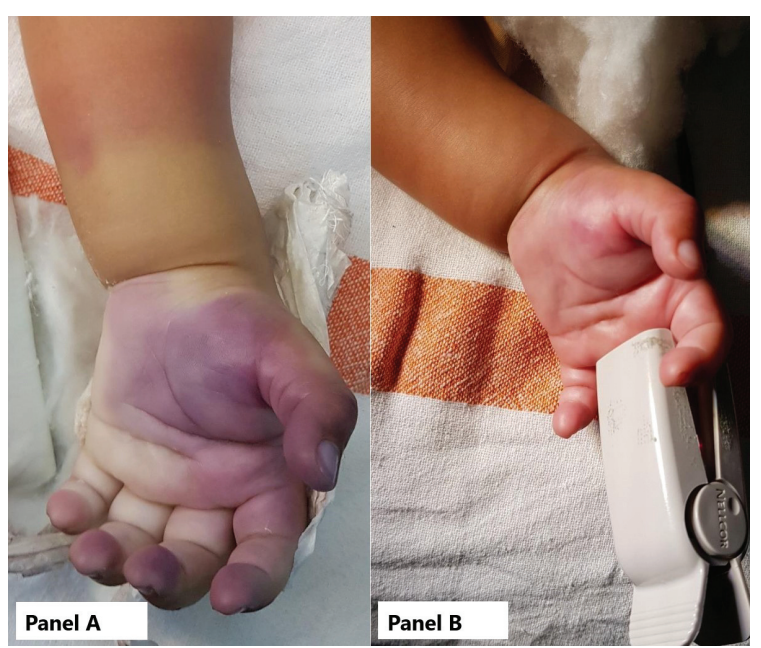

Figure 1. Panel (A) ACS over the left hand. Panel (B) Resolution of features of ACS after conservative management

Extravasation occurs more frequently in veins of pediatric patients, because they are short, smaller in caliber, and fragile ${ }^{(2)}$. The pathophysiology in compartment syndrome due to IV infiltration in infants is different because of the subcutaneous space involvement, expansile skin, and lack of rigid boundaries (3). Moreover, in pediatric patients, bandages, tapes or even splints are commonly used to secure the cannula which delays the detection of any infiltration or extravasation. In our case edema of the hand may be due to infiltration leading to tightening of micropore bandage, which resulted in a further increase in infiltration leading to ACS. Application of topical heparin solution has a role in treating superficial thrombophlebitis as it penetrates through skin very well without any unwanted side effects ${ }^{(4)}$.

Emergent fasciotomy remains the primary treatment for hand compartment syndrome. Nonsurgical treatment includes removal of offending compression, maintenance of perfusion pressures, supplemental oxygen and maintenance of limb at the level of the heart ${ }^{(5)}$. In our case as perfusion of fingers was maintained as indicated by continuous pulse oximetry, we managed hand compartment conservatively.

Prevention and early detection of extravasation is the key to avoid compartment syndrome. For reducing extravasation injuries we recommend a proper selection of veins preferably on the extensor surface, avoidance of obstruction distal to cannulation, multiple punctures, and infusion under high pressure. Early detection of compartment syndrome may be based on clinical findings and some use of noninvasive methods like pulse oximetry (measure perfusion \& oxygenation), near-infrared spectroscopy (measure tissue oxygen), radiofrequency identification implants (measure pressure and temperature fluctuations). The diagnosis of compartment syndrome in this younger population is extremely challenging and a high level of awareness is needed.

\section{REFERENCES}

1. Broom A, Schur MD, Arkader A, Flynn J, Gornitzky A, Choi PD.Compartment syndrome in infants and toddlers. J Child Orthop. 2016;10:453-60. https://doi.org/10.1007/s11832-016-0766-0

2. Talbot SG, Rogers GF. Pediatric compartment syndrome caused by intravenous infiltration. Ann Plast Surg. 2011;67:531-3.

https://doi.org/10.1097/SAP.0b013e3182085915

3. Tobias JD, Hoernschemeyer DG. Near-infrared spectroscopy identifies compartment syndrome in an infant. J Pediatr Orthop. 2007;27:311-3. https://doi.org/10.1097/BPO.0b013e3180326591

4. Kumar N, Kumar P, Singh Y, Mathur SK. Thrombophlebitis of pinna a rare condition: Role of heparin spray. Anesth Essays Res. 2016;10:686-7. https://doi.org/10.4103/0259-1162.191123

5. Chandraprakasam T, Kumar RA. Acute compartment syndrome of forearm and hand. Indian J Plast Surg. 2011;44:212-8.

https://doi.org/10.4103/0970-0358.85342 